Los motivos del interés de esta exploración en el desarrollo de la arquitectura chilena desde las ideas del visitante y del viajero, son diversos: En primer lugar, por el hecho de ser foráneos o de haber vivido en el extranjero, estos arquitectos traen consigo una serie de conocimientos que provienen de tradiciones muy heterogéneas, y que al entrar en contacto con las prácticas, enseñanzas y problemas locales, permiten generar nuevas lecturas e interpretaciones. Por otro lado, las obras de estos arquitectos, dan cuenta de las formas en que la urbe se ha desarrollado, $y$ de esta manera, permiten entender la transformación en el tiempo de la imagen ideal de ciudad. Finalmente, estudiar el papel profesional y académico que estos arquitectos han representado en distintos momentos históricos, nos permiten entender a la vez, la evolución del oficio mismo de la arquitectura, su rol social, su reconocimiento, su especificidad y su relación con el resto de las artes y oficios.

\title{
Arquitectos Viajeros, Arquitectos Visitantes. Acerca de la Formación Académica de la Arquitectura en Chile'. Patricio Pinto
}

\section{DOI: 10.22199/S071985890.2006.0010.00005}

Este artículo plantea una breve (e incompleta) historiografía de la enseñanza de la arquitectura en Chile, a través de las figuras del Arquitecto Visitante y del Arquitecto Viajero. En ambos casos nos referimos a personajes, que por consecuencia de sus viajes o por su formación fuera del país, contribuyeron con su experiencia y conocimiento a la formación de un cierto corpus arquitectónico en Chile, tanto teórico como construído, que si bien es breve, resulta fundamental para explicar de qué manera la figura del arquitecto y el oficio de la arquitectura se fueron abriendo paso en una sociedad que a menudo ha tenido un cierto aire anacrónico, y que se ha mostrado, muchas veces, refractaria a las corrientes modernizadoras en las artes.
En este recorrido, no exhaustivo, compartirán espacio junto a los arquitectos más conocidos, otros que sólo aparecerán nombrados, y seguramente percibiremos la ausencia de muchos otros. Eso quiere decir, que este escrito más que dejar temas cerrados y conclusos, pretende dejar caminos abiertos de exploración, ya que, en lo referente a la historiografía de la arquitectura chilena, y sobre todo al período pre-moderno, queda una larga tarea por desarrollar. Existe muy poca bibliografía y muy pocos estudios respecto de la arquitectura previa a la eclosión del movimiento moderno (con algunas muy notables excepciones). Sin embargo, no es posible entender las peculiaridades de la modernidad chilena sin entender cuales fueron sus antecedentes, que permitieron que la modernidad se arraigara y se re-interpretara, produciendo una serie de obras paradigmáticas que también pertenecen a nuestro patrimonio arquitectónico.

\section{Joaquín Toesca / Arquitectura y Artesania}

Los inicios de la enseñanza de la arquitectura en Chile los podemos situar en la Academia de San Luís, fundada por Manuel de Salas en el año 1797. En esta academia se impartían los cursos de Dibujo y Matemáticas, a cargo del arquitecto italiano Joaquín Toesca, quien se había formado en algunas de las mejores instituciones de su época: la Academia de Barcelona, la Real Academia de Bellas Artes y de San Fernando de Madrid, y la Academia de San Lucas en Roma. Probablemente por recomendación de quien fuera su maestro, Francisco Sabatini, Toesca es enviado a Chile en el año 1780, para hacerse cargo de las obras que en ese momento se estaban realizando en estas tierras, aún pertenecientes al imperio español. De esta manera, Toesca llevará a Chile una tradición que se remonta para continuar la arquitectura barroca clasicista romana, así como la tradición heredada de Palladio, del propio Sabatini y de Vignola.

En Chile, Toesca realizará, entre otras obras, la Real Casa de Moneda 
co, formado hacia 1869, reemplazando las carreras de caballo a la chilena por carreras al estilo inglés. Más tarde, y luego que las instalaciones originales fueran destruidas por un incendio, se levantó el proyecto del arquitecto Josué Smith Solar, iniciado en 1918 y concluido en 1923 (fig. 19,20). Smith Solar había estudiado en Estados Unidos, una circunstancia muy particular en aquel momento, y recibió la influencia de lo que se ha llamado la Escuela de Chicago, de la cual Sullivan es unos de sus máximos exponentes.

\section{Emilio Jecquier y José Forteza /}

\section{La Escuela de Arquitectura de la Universidad Católica de Chile /}

\section{El Arquitecto como Artista}

La Universidad Católica había sido fundada en el año 1888 como respuesta a la educación laica y liberal, impartida en la Universidad de Chile e impulsada por el gobierno de Balmaceda. Dentro de la UC, la arquitectura aparece, primero, como un curso de dibujo instrumental y arquitectónico, dentro de la Escuela de Ingeniería ${ }^{8}$. Uno de los aspectos más destacados de la formación de los arquitectos de la Católica, tiene que ver con la importancia de los ramos de Composición y Dibujo, esto, básicamente, debido a la influencia de la educación beauxartiana impuesta por uno de sus primeros directores, el arquitecto chileno-francés Emilio Jecquier, quien había estudiado en la Escuela Especial de Arquitectura de Emilio Trelat, continuando luego sus estudios en la École des Beaux Arts de París. La influencia de la arquitectura academicista aparece claramente en los proyectos por él realizados, tales como la Casa Central de la Universidad Católica (fig.21), el Museo de Bellas Artes (fig.22), la Estación Mapocho (fig.23,24), el edificio de la Bolsa de Comercio (fig.25) o la desaparecida Estación de Pirque.

Otra de las influencias fundamentales es la que representa el arquitecto catalán José Forteza Ubach, quien llegó a Chile en el año 1889 luego de haber participado en la Exposición Universal de 1888 en Barcelona (fig.26,27).

Forteza estudia en la Escuela Superior de Arquitectura de Barcelona durante los mismos años en que estudiara Gaudí, y; por lo tanto, participa del debate arquitectónico que, en este momento, se producía en Europa, debate del que, en alguna medida, el Modernisme catalán fue una respuesta. Estos problemas se referían, someramente, a temas técnicos referidos a los nuevos materiales constructivos, el debate referido al estilo con el cual se debía construir, y, finalmente, la polémica en torno al ornamento.

Esta herencia es la que Forteza traerá a Chile y transmitirá a sus alumnos, tanto en la Universidad Católica como en la Universidad de Chile. Si bien la arquitectura que realiza es, en una primera lectura, de un neo-gótico historicista, es posible rastrear en algunos de sus edificios, especialmente en el desaparecido Palacio Undurraga (fig.28,29,30), una cierta voluntad de transparencia y ligereza en las fachadas, a través del uso de una estructura de acero de grandes luces, que permite, a su vez, grandes cerramientos acristalados

\section{Sergio Larraín García-Moreno /}

\section{Los Albores del Movimiento Moderno en Chile}

En una entrevista realizada por Humberto Eliash al arquitecto Sergio Larraín García-Moreno, este último refiere una anécdota que nos permite entender el momento de transición en el que se encontraba la arquitectura en los inicios del siglo XX. Sergio Larraín ingresa a la Escuela de Arquitectura de la Universidad Católica el año 1924, recién llegado de París, en donde gracias a su parentesco y amistad con el poeta Vicente Huidobro, había tenido contacto con muchos de los personajes de la vanguardia parisina de aquellos años: "Yo creo que mi entrada a la escuela me puso muy vanidoso, porque yo sentí que estaba en otro nivel cultural, respecto de todo el curso. Yo sabía cosas que nadie había oído, y no sólo sabía cosas que nadie había oído en mi curso, sino que ningún profesor había oído... Recuerdo que a don José Forteza, que era profesor, le presté todas las obras de Le Corbusier... Les decía a los profesores: Lo que ustedes nos enseñan, esto ya no existe, esto ya no es arquitectura... La única persona que me oyó fue don José Forteza, y me dijo: Hijito, présteme esos libros. Entonces, le presté los libros y me los devolvió, pero, desgraciadamente, les sacó las tapas y me los empastó con unas bien horrorosas, y así están ahora. De todas formas aprecié este gesto de don José...y me dijo que le parecían muy interesantes" 9 .

Es este el momento en que llegamos a la arquitectura de principios del siglo XX en Chile, una arquitectura en la que teoría y pensamiento moderno aparecen aún escondidos bajo una cáscara de ornamentaciones y estucos, tal como lo podemos ver en los proyectos de Sergio Larraín de estos años, algunos radicalmente modernos (de hecho el edificio Oberpaur es considerado el primer edificio Moderno construido en Chile), simultáneos a otros neo-clásicos (fig.31,32); en definitiva, un momento en el que es posible encontrar el germen de la nueva arquitectura que está a punto de llegar.

Los libros de Le Corbusier, empastados clásicamente por Forteza en cuero con aplicaciones doradas, representan una síntesis de este momento, en el que elementos antiguos y modernos se entremezclan sin un límite claro. La viajera obra teórica radicalmente moderna, se manifiesta envuelta en el anacrónico envoltorio de un arquitecto visitante.

Notas

1. Este artículo está basado en una lección de una serie realizada a distancia, en la Escuela de Arquitectura de la Universidad Mayor, como iniciativa de la profesora Pilar Silva Mondselewsky, a través de una invitación hecha a despacho Ona Arquitectos de Barcelona, el año 2005.

2. Ver: Santiago a comienzos del siglo XIX. Crónicas de los Viajeros. Guillermo Feliú Cruz. Editorial Andrés Bello, Santiago de Chile, 2001

3. Curso de Arquitectura. Francois Brunet de Baines. Santiago, Chile. Imprenta Berlin. 1853.

4. Las Bellas Artes en Chile. Anales de la Universidad de Chile, 1866. p.276.

5. Ver: Santiago de Chile. Armando de Ramón. Ed. Sudamericana. 2000.

6. Ver: "Pre-Texto" en: El Peso de la Noche. Nuestra frágil fortaleza histórica. Alfredo Joselyn-Holt. Ed. Espasa Calpe Ariel, Argentina, 1997.

7. Cuando Chile Cumplió Cien Años. Alfonso Calderón. Ed. Quimantú. Santiago de Chile. 1973.

8. Ver: Cien Años de Arquitectura de la Universidad Católica. Wren Strabucci, Editor. Ediciones ARQ 1994.

9. Entrevista a Sergio Larrain García-Moreno, 28 de abril de 1982. En: “La Arquitectura Moderna 1920-1970", Humberto Eliash, Santiago de Chile, 1982.

Casa de

2.3. Catedralde

5ive

6. Vista de Santiago desde la Terraza del Hidalgo del cerro Santa Lucia, hacia

6. Portada del libro "Curso de Arquitectura". Francois Brunet de Baines.

7. Francoise Brunet de Baines, Teatro Municipal de Santiago. Con la participación de Ambrose Hénault. En la actualidad, este edificio se

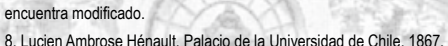

9,10. Palacio de 'La Alambra', arquitecto Manuel Addunate Avaria. Mandada a construir originalmente por Franciscol Inacio Ossa el año 1860, y que da cuenta del espiritu proclive al exotismo presente en la época, espiritu del que el Palacio Urmeneta (1871), es otro buen ejemplo. 11, 12. Emilio Doyère. Palacio de los Tribunales. 1905-1930.

13. Cerro Santa Lucia a comienzos de siglo. Se puede observar el acceso monumental y la Fuente de Neptuno, asi como los miradores superiores y la abundante vegetación. En el proyecto participa el arquitecto Manuel Aldunate. 14. Cerro Santa Lucia visto desde la calle Moneda. Contrasta el lujo de las construcciones del cerro con la simpleza y austeridad de las

15.

15. Palacio Cousiño. Arquitecto Paul Lathoud, 1873-1878.

16, 17, 18. Parque Cousiño. Vistas varias en postales de la época.

19, 20. Club Hipico de Santiago. Arquitecto Josué Smith Solar. 1918-1923.

21. Edificio de la Universidad Católica. Arquitectos Emilio Jecquier y Manuel Cifuentes, 1909-1917. Este último, el primer arquitecto titulado de la Escuela de Arquitectura de la UC.

22. Edificio del Museo de Bellas Artes. Arquitecto Emilio Jecquier, 1910. Inaugurado con motivo de las celebraciones del primer Centenario de la Independencia.

23,24. Estación Mapocho. Arquitecto Emilio Jecquier

25. Edificio de la Bolsa de Comercio. Arquitecto Emilio Jecquir.

26. 27. Pabellón de Sevilla proyectado por José Forteza con motivo de la Exposición Universal de Barcelona de 1888. ediffio del Caté laurant de la Exposición, proyectado por el arquitecto Domenech i Montaner, y luego terminado por Forteza, ras la renuncia de Doméne 28, 29, 30. Distintas vistas de la época del Palacio Undurraga (demolido), Arquitecto José Forteza.

28, 29, 30. Distintas vistas de la época del Palacio Undurraga (demolido), Arquitecto José Forteza.
31, 32. Proyectos de la oficina Arteaga-Larrain, entre ellos, el edificio Oberpaur, de 1929, considerado el primer edificio moderno del pais.

Patricio Pinto D. / patopinto@gmail.com

Arquitecto Pontificia Universidad Católica de Chile.

Máster Historia, Arte, Arquitectura, Ciudad, ETSAB, UPC, Barcelona, España, 2001.

Doctor (c) Teoría e Historia de la Arquitectura, UPC. 